\title{
Brain Cooling in Babies: Are We Ready for Clinical Trials in Developing Countries?
}

\author{
SUdHIN ThaYYIL \\ NIHR Clinician Scientist and Honorary Consultant Neonatologist, Institute for Women's Health, 74 Huntley Street, \\ University College London, London WC1E 6AU, United Kingdom. s.thayyil@ich.ucl.ac.uk
}

$\int\left[\begin{array}{l}n \\ n\end{array}\right.$ nvestment in science improves the health and wealth of the society - rescue hypothermic neuroprotection is one such striking example. Two decades of experimental and clinical research and meta-analysis of the clinical trials from industrialised countries conclusively demonstrates that whole body or selective head cooling reduces the death and disability following neonatal encephalopathy (NE) [1]. Thus, neuroprotection is now a reality benefiting approximately one thousand babies affected by NE in the UK every year and has saved the National Health Service one billion pounds (Rs 7000 crores) in the past three years National Perinatal Epidemiology Unit (NPEU) Cooling Registry.

Should the cooling story end here and we move on to newer neuroprotectants? Often forgotten is the need of the under privileged; approximately quarter million deaths occur from NE (now called as intrapartum related deaths) in India every year and possibly an equal number get disabled for life [2]. A substantial proportion of these deaths still occur in the community or in hospitals without provisions for good basic neonatal care and resuscitation [2]. There may be reservations in deploying hypothermia outside the setting of an intensive care unit, for example, in the UK, encephalopathic infants are transferred to selected tertiary or secondary centres with cooling expertise and often passive cooling is instigated during transfer.

Many secondary and tertiary neonatal units in India, particularly in the private settings do have facilities for providing good quality neonatal intensive care and monitoring. Is it ethical to with hold rescue hypothermic neuroprotection in such settings? Two key issues need to be considered. First is the availability of an effective and inexpensive cooling equipment. In this month's Indian Pediatrics, Thomas and colleagues from Christian Medical College, Vellore elegantly demonstrate that therapeutic hypothermia can be effectively administered using ice packs. The data on temperature stability is consistent with that of the multicentre Infant Cooling Evaluation (ICE) trial where whole body cooling using ice along with rigorous monitoring of core temperature showed a significant improvement in survival without disability [3]. A flip side is the additional nursing resources required to maintain the target temperature and the possibility of temperature fluctuations and over cooling that may result in loss of neuroprotection [4].

Second and a far more important factor is the differences in population co-morbidities, which raises the question whether hypothermia would be indeed neuroprotective or even safe in this population. Several factors need to be considered and the jury is still out. The neuroprotective effect of hypothermia is crucially dependent on the start of the treatment within a narrow window period before the onset of secondary energy failure. Delayed hospital admissions often in obstructed labor, intrauterine growth retardation, lack of effective neonatal transport networks with optimal neurocritical care support during transfer in most Indian cities, and long delays in carrying out emergency caesarean sections may mean that this window period may well be lost in a significant proportion of infants with encephalopathy before cooling is initiated. 
Furthermore, the incidence of perinatal infections and chorioamnionitis in low and midincome countries (LMIC) is substantially higher than in industrialised countries. Experimental and epide-miological evidence suggests that the brain injury may be more severe in a dual hit infectionasphyxia scenario and therapeutic hypothermia may be less neuroprotective. Pilot studies of therapeutic hypo-thermia by Guhan and colleagues at Calicut Medical College using state of art Magnetic resonance techniques like tract based spatial statistics (TBSS) supports this hypothesis; not only the pattern of brain tissue injury of NE infants was different to that of industrialised countries in this study, but the response to hypothermia was also altered (unpublished data).

Another interesting difference is the low mortality in the control arm of the 'in trial' NE population seen in several pilot studies from LMIC [5], as opposed to the clinical trials from industrialised countries. This may be due to the use of less stringent inclusion criteria and thus recruiting infants with milder encephalopathy who may not be at risk of long term adverse outcomes any way. It is possible that severely affected infants are either still born or die soon after birth.

Neonatologists are only too aware of the situations where over enthusiasm and premature implementation of research evidence resulted in disastrous consequences, for example steroid treatment for prevention of chronic lung disease and prophylactic use of antibiotics for preterm labor resulting in an increase in cerebral palsy [6]. On the other hand high quality randomised control trials in LMIC are exceedingly challenging and require strategies for improving the research infrastructure and long term follow up. A joint effort between neonatologists, trialists, cooling experts, funding bodies and governmental organisations may be required for rigorous evaluation of rescue neuroprotection in LMIC.

Meanwhile the clinicians in these settings should consider whether the individual cases are similar to the 'in trial' population of the major cooling studies before offering rescue neuroprotection. 'First do no harm' and continuing normothermia as standard of care may be a more prudent option until good evidence is available on the contrary.

Funding: National Institute for Health Research, United Kingdom (Clinician Scientist Award).

Competing interests: None stated.

\section{REFERENCES}

1. Edwards A, Brocklehurst P, Gunn A, Halliday H, Juszczak $\mathrm{E}$, Levene $\mathrm{M}$, et al. Neurological outcomes at 18 months of age after moderate hypothermia for perinatal hypoxic ischaemic encephalopathy: synthesis and meta-analysis of trial data. BMJ. 2010;340:C363.

2. Lawn JE, Kinney M, Lee AC, Chopra M, Donnay F, Paul $\mathrm{VK}$, et al. Reducing intrapartum-related deaths and disability: Can the health system deliver? Int J Gynaecol Obstet. 2009;170:S123-42.

3. Jacobs SE, Stewart M, Inder T, Doyle LW, Morley CJ. ICE: the Australian cooling trial for hypoxic-ischemic encephalopathy - in hospital outcomes. Proceedings of the Hot Topics in Neonatology Conference. Washington, DC, 2008.

4. Merchant RM, Abella BS, Peberdy MA, Soar J, Ong ME, Schmidt GA, et al. Therapeutic hypothermia after cardiac arrest: unintentional overcooling is common using ice packs and conventional cooling blankets. Crit Care Med. 2006;34:S490-4.

5. Zhou WH, Cheng GQ, Shao XM, Liu XZ, Shan RB, Zhuang DY, et al. Selective head cooling with mild systemic hypothermia after neonatal hypoxic-ischemic encephalopathy: a multicenter randomized controlled trial in China. J Pediatr. 2010;.157:367-72.

6. Kenyon S, Pike K, Jones DR, Brocklehurst P, Marlow N, Salt A, et al. Childhood outcomes after prescription of antibiotics to pregnant women with spontaneous preterm labour: 7-year follow-up of the ORACLE II trial. Lancet. 2008;372:1319-27. 